\title{
E2 multimeric scaffold for vaccine formulation: immune response by intranasal delivery and transcriptome profile of E2-pulsed dendritic cells
}

Maria Trovato ${ }^{1}$, Francesco Maurano ${ }^{2}$, Luciana D'Apice ${ }^{1}$, Valerio Costa ${ }^{3}$, Rossella Sartorius ${ }^{1}$, Fausta Cuccaro ${ }^{1}$, Sean P. McBurney ${ }^{4}$, Shelly J. Krebs ${ }^{4}$, Antonella Prisco ${ }^{3}$, Alfredo Ciccodicola ${ }^{3,5}$, Mauro Rossi ${ }^{2}$,

Nancy L. Haigwood ${ }^{4}$ and Piergiuseppe De Berardinis ${ }^{1 *}$

\begin{abstract}
Background: The E2 multimeric scaffold represents a powerful delivery system able to elicit robust humoral and cellular immune responses upon systemic administrations. Here recombinant E2 scaffold displaying the third variable loop of HIV-1 Envelope gp120 glycoprotein was administered via mucosa, and the mucosal and systemic immune responses were analysed. To gain further insights into the molecular mechanisms that orchestrate the immune response upon E2 vaccination, we analysed the transcriptome profile of dendritic cells (DCs) exposed to the E2 scaffold with the aim to define a specific gene expression signature for E2-primed immune responses.

Results: The in vivo immunogenicity and the potential of E2 scaffold as a mucosal vaccine candidate were investigated in BALB/c mice vaccinated via the intranasal route. Fecal and systemic antigen-specific IgA antibodies, cytokine-producing $\mathrm{CD}^{+}$and $\mathrm{CD}^{+}$cells were induced assessing the immunogenicity of E2 particles via intranasal administration. The cytokine analysis identified a mixed T-helper cell response, while the systemic antibody response showed a prevalence of IgG1 isotype indicative of a polarized Th2-type immune response. RNA-Sequencing analysis revealed that E2 scaffold up-regulates in DCs transcriptional regulators of the Th2-polarizing cell response, defining a type 2 DC transcriptomic signature.

Conclusions: The current study provides experimental evidence to the possible application of E2 scaffold as antigen delivery system for mucosal immunization and taking advantages of genome-wide approach dissects the type of response induced by E2 particles.
\end{abstract}

Keywords: E2 scaffold, Vaccine, Mucosal immunity, Bone marrow-derived dendritic cells, RNA-Sequencing, Transcriptome profile, Th2

\section{Background}

The E2 system is a delivery vehicle in which antigenic determinants are inserted on the surface of an icosahedral scaffold formed by the acyltrasferase component (E2 protein) of the multienzyme pyruvate dehydrogenase (PDH) complex from Geobacillus stearothermophilus [1, 2]. E2 naturally serves as a docking unit for other large PDH

\footnotetext{
*Correspondence: p.deberardinis@ibp.cnr.it

${ }^{1}$ Institute of Protein Biochemistry, C.N.R, Via Pietro Castellino 111, Naples 80131, Italy

Full list of author information is available at the end of the article
}

subunits. This property makes it an excellent scaffold for the presentation of $\mathrm{N}$-terminal fused heterologous antigens. The scaffold can be refolded in vitro to produce pure or chimeric particles similar to virions in size and complexity, it is able to confer high immunogenicity to the displayed determinants, and it is suitable for vaccine formulations [3-6]. Various protein domains, such as the HIV-1 Envelope (Env) V3 loop, can be assembled into lipopolysaccharide (LPS)-free E2 recombinant vaccines, and we previously demonstrated that their systemic administrations are able to elicit potent binding antibodies and T-cell responses in 
mice, as well as autologous neutralizing antibodies in rabbits [7].

A shared feature of many pathogens is that the infection occurs or initiates at a mucosal surface. While systemic vaccination offers protection against pathogens such as polio and influenza viruses, induction of mucosal immunity is required for effective protection against pathogens such as HIV, human papillomavirus, herpes viruses, Vibrio cholera and the Mycobacterium species [8-13]. Antibodies patrolling the mucosal epithelium appear to play a crucial role in blocking HIV-1 mucosal challenge [14]. Therefore, it is necessary to develop adequate mucosal vaccination protocols for this type of infection.

Understanding the immunological mechanisms of vaccination is of paramount importance for the rationale design of a vaccine. Recently, the use of systems biology approaches gave an important contribution to elucidate the fundamental mechanisms by which the innate immune system orchestrates protective immune responses triggered by vaccination [15-17]. High-throughput sequencing can be applied to explore cell transcriptome and to identify differences in gene expression and alternative splicing. In vaccinology, gene expression patterns induced by priming antigen presenting cells (APCs) could be used to predict antigen immunogenicity and the type of T-helper cell polarization, and/or help to select the appropriate adjuvant to administer in the vaccine formulation.

As proof-of-concept, here we report the immunogenicity of E2 scaffold in a model of mucosal vaccination, and show that intranasal administration of E2-based vaccines is able to induce mucosal and systemic immune responses. Through RNA-Sequencing (RNA-Seq) analysis, we attempt to identify the molecular signatures that could account for E2-primed immune responses, and analyze the gene expression profile of bone marrow-derived dendritic cells (BMDCs) pulsed with E2 scaffold compared to un-pulsed cells.

\section{Methods}

Purification of HIV-1 E2-based multimeric scaffolds

Expression and purification of E2 wild type (E2wt) and recombinant E2 multimeric particles displaying the HIV-1 SF162 Envelope V3 loop peptide [amino acid 291-336, reference strain HIV-HXB2; (Env(V3)-E2)], were performed following previously described protocols [7, 18]. The purified 1.5MDa E2 60-mer particles were subjected to endotoxin (LPS) removal by Triton X-114 (Sigma Aldrich, Milan, Italy) phase separation [19] and to detergent removal by using Thermo Scientific Pierce Detergent Removal Resin (Thermo Fisher Scientific, IL, USA). The final particles were tested for endotoxin using the Limulus Amebocyte Lysate (LAL) Assay (QCL-1000, Lonza, Basel, Switzerland), according to the manufacturer's instructions and were less than $0.05 \mathrm{EU} / \mathrm{ml}$.

\section{Antibodies, reagents and synthetic peptides}

For flow cytometric analysis, fluorescein isothiocyanate (FITC)-conjugated anti-mouse CD8 (clone 53-6.7) and phycoerythrin (PE)-conjugated anti-mouse IFN- $\gamma$ (XMG1.2) were purchased from Biolegend (San Diego, CA). For Intracellular Cytokine Staining (ICS) assay, the $\mathrm{H}-2 \mathrm{~d}$ MHC class I-restricted synthetic IGPGRAFYA $(311-318)$ peptide, corresponding to residues 311-318 of the HIV-1 Env V3 loop, was purchased from PRIMM srl (Naples, Italy). For analysis of fecal IgA, serum IgA and IgG, the HIV-1 SF162 clade B V3 peptide (PNNNTRKSITIGPGRA FYATGD) and the V3 scrambled peptide (PNNNTRKSI FYRGAPGITATGD) were purchased from Invitrogen (Carlsbad, CA) and Genscript (Piscataway, NJ), respectively. Mouse IL-4 and IFN- $\gamma$ ELISA MAX ${ }^{\mathrm{TM}}$ Standard SET kits were obtained from BioLegend. Mouse $\mathrm{CD} 4^{+}$ $\mathrm{T}$ cell isolation kit was purchased from Miltenyi Biotec (Bergisch Gladbach, Germany). For the quantitative measurement of IgA antibodies in fecal samples, RayBio ${ }^{\circ}$ Mouse IgA ELISA Kit was purchased from RayBiotech, Inc. (Norcross, GA, USA).

\section{Mucosal vaccination with E2-based vaccines}

Female BALB/c (H-2d MHC) mice, 6 to 12 week-old, were purchased from Charles River Laboratory (Lecco, Italy) and housed under specific pathogen free conditions at the Animal Facility of the Institute of Food Science of C.N.R., Avellino, Italy (accreditation no. DM.161/99). Groups of five BALB/c mice were intranasally immunized with $50 \mu \mathrm{g}$ of E2wt, Env(V3)-E2, or Env(V3)-E2 with $1 \mu \mathrm{g} /$ mouse of cholera toxin (CT) adjuvant (Sigma Aldrich), at weekly intervals for 7 weeks. The intranasal (i.n.) administration was carried out by inoculating $20 \mu \mathrm{l}$ of antigens to the nostril. Fecal pellets were collected at weekly intervals, weighed, homogenized at a concentration of $10 \mathrm{mg} / \mathrm{ml}$ in $1 \times$ phosphate buffered saline (PBS), $0.01 \%$ sodium azide (Sigma Aldrich), and centrifuged at 10,000 g for $10 \mathrm{~min}$ to remove debris as previously described [20]; supernatants were recovered and stored frozen. One week after the final boost, mice were sacrificed to collect spleen and serum samples.

\section{ELISA assay for detection of IgA and IgG antibodies}

Analysis of fecal IgA, serum IgA and IgG antibodies (IgG, IgG1, and IgG2a) were performed by in house ELISA as previously described [20] using the synthetic HIV-1 SF162 V3 peptide, V3 scrambled peptide, Env(V3)-E2 or E2wt proteins as antigens. Briefly, 96-well ELISA plates (MaxiSorp ${ }^{\mathrm{TM}}$, NUNC, NY) were precoated with $100 \mu \mathrm{l} /$ well of $2 \mu \mathrm{g} / \mathrm{ml}$ of E2 antigens or V3 synthetic peptides in $1 \times$ PBS and incubated overnight at $4{ }^{\circ} \mathrm{C}$. Plates were washed 4 times with PBS containing $0.05 \%$ Tween-20 (Sigma Aldrich) and blocked by adding $200 \mu \mathrm{l} /$ well of PBS containing $2 \%$ bovin serum albumin 
(Sigma Aldrich) at room temperature (RT) for $2 \mathrm{~h}$. After the incubation, plates were washed 4 times with washing buffer. Two-fold serial dilutions of sera (starting at 1:100 and ending to $1: 12,800)$ and $100 \mu \mathrm{l}$ of soluble fecal extracts were added to the plates and incubated at RT for $2 \mathrm{~h}$. All samples were tested in duplicate. After washing, plates were incubated with 1:2,000 dilution of peroxidaseconjugated rabbit anti-mouse IgA, IgG, IgG1, or IgG2a antibodies (Santa Cruz Biotechnology, Dallas, USA). Results were expressed as absorbance values after blank subtraction or as reciprocal endpoint titer of the last dilution exhibiting $\mathrm{OD}_{450} \geq 0.12$. The highest dilution tested was 1:128,000. Serum titers of $<1: 100$ were considered negative and were reported in figures with an arbitrary titer value of 1:10. Levels of total IgA antibodies in soluble fecal extracts $(100 \mu \mathrm{l}$ of $10 \mathrm{mg} / \mathrm{ml})$ were quantified in duplicates using the $\mathrm{RayBio}^{\circ}$ Mouse IgA ELISA Kit, according to the manufacturer's instructions. The Env(V3)-specific IgA antibodies were normalized by dividing the specific $\mathrm{OD}_{450}$ readings of IgA by the total IgA concentration in $\mathrm{ng} / \mathrm{ml}$ [21], measured in fecal samples at week 4 for each animal from Env(V3)-E2 and Env(V3)-E2 + CT groups.

\section{Detection of IL-4 and IFN- $\gamma$}

Spleen cells were isolated from BALB/c mice mucosally immunized with E2wt or $\operatorname{Env}(\mathrm{V} 3)-\mathrm{E} 2$ administered with CT. Splenocytes from each group were pooled and used as antigen presenting cells (APCs). Afterwards, $\mathrm{CD}^{+} \mathrm{T}$ cells were purified from pooled splenocytes using the $\mathrm{CD}^{+}{ }^{+}$T cell isolation kit. $1 \times 10^{5} \mathrm{CD}^{+}$T cells were incubated with $1 \times 10^{5} \gamma$-irradiated APCs preloaded or not with $50 \mu \mathrm{g} / \mathrm{ml}$ of E2wt, or Env(V3)-E2. Cells were cultured overnight in $0.2 \mathrm{ml}$ of RPMI 1640 (Lonza) medium supplemented with $50 \mu \mathrm{M}$ 2-mercaptoethanol, $1 \mathrm{mM}$ sodium pyruvate, $100 \mathrm{U} / \mathrm{ml}$ penicillin, $100 \mu \mathrm{g} / \mathrm{ml}$ streptomycin, and $10 \%$ Fetal Calf Serum (FCS) (all from GIBCO, Milan, Italy). Supernatants $(0.1 \mathrm{ml} /$ well $)$ were assayed in duplicate for detecting IL-4 and IFN- $\gamma$, using the mouse IL- 4 and IFN- $\gamma$ ELISA MAX ${ }^{\mathrm{TM}}$ Standard SET kits, according to the manufacturer's instructions.

\section{Analysis of CD8 T-cell response}

The antigen-specific CD8 T-cell response was assessed by intracellular cytokine staining (ICS) assay on spleen cells isolated from mice described above co-cultured in vitro $\left(2.5 \times 10^{6}\right.$ cells $\left./ \mathrm{ml}\right)$ for 6 days with $\gamma$-irradiated $(10,000 \mathrm{rad})$ LPS-blasts $\left(1.25 \times 10^{6}\right.$ cells $\left./ \mathrm{ml}\right)$ prepulsed with $10 \mu \mathrm{g} / \mathrm{ml}$ of MHC-I restricted V3 peptide. IFN- $\gamma$ production was evaluated on $\mathrm{CD}^{+}$gated $\mathrm{T}$ cells by FACS (Fluorescence Activated Cell Sorter) analysis using FACSCanto II flow-cytometer and DIVA (Data-Interpolating Variational Analysis) software (Becton Dickinson, Fullerton, CA), as previously described by Jaworski et al. [7].
BMDCs, RNA-Seq library production, sequencing and data analysis

Bone marrow-derived dendritic cells (BMDCs) were generated according to previously described protocols [22]. Briefly, bone marrow cells were collected by flushing tibias of C57BL/6 mice (Charles River Laboratory) with complete medium (RPMI 1640, $50 \mu \mathrm{M}$ 2-mercaptoethanol, $1 \mathrm{mM}$ sodium pyruvate, $100 \mathrm{U} / \mathrm{ml}$ penicillin, $100 \mu \mathrm{g} / \mathrm{ml}$ streptomycin, 10 \% FCS). Cells were seeded in bacteriological Petri dishes in complete medium supplemented with $200 \mathrm{U} / \mathrm{ml}$ of recombinant murine granulocyte-macrophage colony stimulating factor (GM-CSF, Peprotech, NJ, USA) for 7 days. Immature cells were harvested and incubated or not for 1 more day with $50 \mu \mathrm{g} / \mathrm{ml}$ of LPS-free E2wt antigen at a final concentration of $2.5 \times 10^{6}$ cells $/ \mathrm{ml}$. Total RNA was extracted from untreated or E2-pulsed BMDCs using Tri Reagent (Sigma Aldrich) according to manufacturer's protocol. RNA integrity was assessed as described in Costa et al. [23]. Paired-end libraries (100 x 2 bp) prepared using TruSeq RNA Sample Preparation Kit (Illumina Inc., San Diego, CA) were sequenced on Illumina HiSeq2000 platform. About 200 million paired-end reads were sequenced. Quality was assessed using FastQC (http://www.bioinformatics.babraham.ac.uk/projects/fastqc/). TopHat version 2.0.10 [24] was used to map reads on reference mouse genome (mm9) and RefSeq mouse transcripts annotation with default parameters. More than $95 \%$ of sequenced reads uniquely mapped to $\mathrm{mm} 9$. Such reads were used for further analyses. Coverage files were produced using BEDTools and loaded on UCSC Genome Browsers to analyze gene-specific features. Gene expression was measured using Cufflinks 2 [25]. Cuffdiff and CummeRBund [26] were used to identify differentially expressed genes using normalized expression values (FPKM, Fragments Per Kilobase of transcript and Million of mapped reads). An arbitrary threshold of 0.05 FDR (False Discovery Rate) and 1 FPKM in at least one condition was used to filter out differentially expressed genes. Gene ontology and pathway analysis were performed using DAVID (Database for Annotation, Visualization and Integrated Discovery) [27].

\section{Statistics}

Statistical analyses were performed using the unpaired two-tailed Student's $t$-test. Differences were considered statistically significant when $P<0.05$.

\section{Results}

\section{Dissection of fecal antibody responses after mucosal} immunization

To determine whether HIV-1 epitopes displayed on the surface of E2 scaffold could elicit antigen-specific mucosal immune responses, the V3 loop of HIV-1 Envelope gp120 glycoprotein was expressed as an $\mathrm{N}$-terminal fusion to the 
catalytic core domain of E2 and purified according to previously described methodologies [7]. The HIV-1 clade B primary isolate SF162 (Tier 1) V3 portion (46 aminoacids total) inserted into the E2 scaffold contained the epitope $\left(\mathrm{G}_{312} \mathrm{PGR}_{315}\right)$ recognized by the human anti-V3 monoclonal neutralizing antibody (NmAb) 447-52D and the $\mathrm{H}-2 \mathrm{~d}$ restricted CTL (cytotoxic T lymphocyte) epitope $\left(\mathrm{I}_{311}\right.$ GPGRAFYA $\left.{ }_{319}\right)$. The resulting vaccines were nonreplicative multimeric particles formed by HIV-1 antigens inserted on the surface of $\mathrm{E}_{60 \text {-mer }}$ scaffold protein, and we evaluated their immunogenicity as mucosal vaccines in mice. To this end, BALB/c mice of the $\mathrm{H}-2 \mathrm{~d}$ haplotype ( $n=5$ per group) were intranasally immunized with Env(V3)-E2, administered with or without the adjuvant cholera toxin $(\mathrm{CT})$. Vaccinations were conducted weekly for seven weeks. Fecal pellets were collected after each immunization.

Mucosal IgA responses were measured against E2wt (Fig. 1a), the synthetic HIV-1 SF162 V3-specific peptide, corresponding to residues 301-322 of the V3 loop presented on the E2 surface, and V3 scrambled peptide (Fig. 1b). Figure 1a shows the mean absorbance values for antibodies obtained in feces against the E2 scaffold reaching a plateau after 4 weeks of treatment with the Env(V3)-E2 vaccines in presence or absence of CT. After the first immunization, all vaccinated mice generated anti-carrier E2-specific responses that were enhanced following subsequent administrations (Fig. 1a) and sustained throughout the course of the experiment. No statistically significant differences $(P>0.05)$ in the absorbance values of E2-binding antibodies were observed between groups of immunized mice, suggesting that E2 scaffold is also immunogenic at mucosal sites in the absence of added adjuvant. Concerning V3-specific antibody responses, Env(V3)-E2 + CT group showed at week 7 significantly higher levels of V3-binding antibodies compared to Env(V3)-E2 group $(P=0.0051)$ (Fig. 1b). This difference remains significant after normalization of the $\operatorname{Env}(\mathrm{V} 3)$-specific IgA responses to whole IgA concentration $(P=0.0262$, Fig. 1c). Thus, in contrast to antibody responses to the E2 carrier, adjuvant was essential to induce detectable antigenspecific mucosal immune responses.

Overall, this experiment demonstrates that intranasal administration of E2-based vaccines is able to induce anti-Env antigen-specific antibodies in fecal samples.

\section{Analysis of systemic antibody and CD4 T cell responses}

Since the strongest V3-specific IgA response was observed following inoculation of Env(V3)-E2 administered with adjuvant, we focused our interest on this group (Env(V3)-E2 + CT) for additional experiments. The E2 wild type group (E2wt) was included to compare the responses generated against the carrier. We assessed the systemic antibody response against the E2 scaffold and
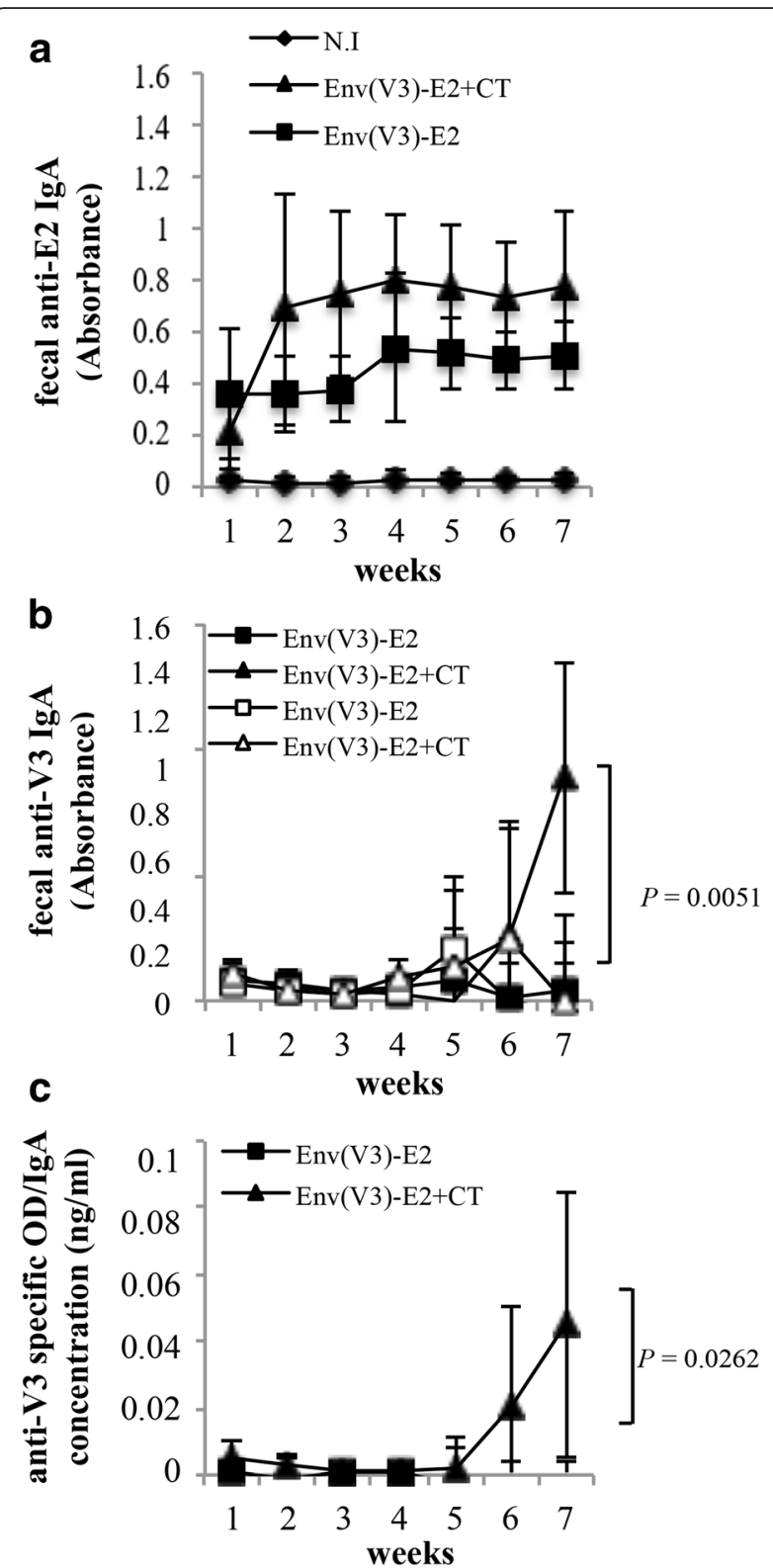

Fig. 1 Mucosal antibody responses. BALB/c mice $(n=5)$ were intranasally immunized with: Env(V3)-E2 particles administered with (triangle) or without (square) CT adjuvant. At weekly intervals fecal pellets were collected to determine the presence of E2-binding antibodies and Env-specific IgA. Naïve mouse group (N.I., $n=5$, diamonds) was used as control of background response. Fecal anti-E2 and anti-V3 IgA antibodies were measured by coating in ELISA assay (a) E2wt protein or (b) synthetic HIV-1 SF162 V3 peptide (filled triangles or squares), and scrambled peptide (empty triangles or squares). A representative experiment out of two is shown. Graphs show the mean absorbance values ( \pm S.D.) of fecal samples from mice of each group at the indicated time points; statistical significance was determined using the unpaired two-tailed Student's $t$-test, $P$ value is reported. (c) Specific levels of IgA antibodies to V3 peptide as defined by ELISA OD 450 readings normalized to whole IgA concentration in soluble fecal extracts from mice immunized with Env(V3)-E2 particles administered with (triangle) or without (square) CT adjuvant 
the $\operatorname{Env}(\mathrm{V} 3)-\mathrm{E} 2$ protein in serum samples by ELISA. All animals developed high titers $\left(\sim 10^{4}\right)$ of anti-carrier E2 specific IgG antibodies (Fig. 2a). Mice immunized with Env(V3)-E2 particles developed significantly higher titers of Env(V3)-E2 binding antibodies compared to the E2 wild type control group (Fig. 2a). To specifically detect antibodies raised against the 447-52D core epitope we used the V3 synthetic peptide as antigen (Fig. 2b and c), and found that $\operatorname{Env}(\mathrm{V} 3)-\mathrm{E} 2$ particles were able to elicit serum IgG (Fig. 2b) and IgA (Fig. 2c) V3-binding antibodies. These results indicate that intranasal delivery of E2 is able to elicit mucosal and systemic antibody responses directed toward the 447-52D core epitope of the HIV-1 V3 loop region.

In order to examine the type of immune responses induced in vivo by E2 vaccination following the intranasal route, we analyzed the isotype ratios of serum IgG1/ IgG2a and evaluated the induction of antigen-specific $\mathrm{CD}^{+} \mathrm{T}$ cells in vaccinated mice.

We first determined the isotype of anti-V3 antibodies in sera collected at the end of vaccination. Intranasal administration of Env(V3)-E2 based vaccines induced a preferential increase of IgG1 (Fig. 3a and c) against the V3 peptide over the IgG2a isotype (Fig. 3b and c), suggesting a polarization of $\mathrm{CD} 4^{+} \mathrm{T}$ cells toward the Th2 subset, consistent with findings previously reported by us $[5,28]$. We next evaluated whether mucosal administration of Env(V3)-E2 induced Th2 cells. To this end, we characterized the type of the cellular immune response by measuring cytokine production from splenic $\mathrm{CD} 4^{+} \mathrm{T}$ cells. Env(V3)-E2 particles elicited antigen-specific $\mathrm{CD} 4^{+} \mathrm{T}$ cells able to produce the Th2 cytokine IL-4 (Fig. 3d). However, following the intranasal vaccination regimen, we also detected IFN- $\gamma$ production in $\mathrm{CD}^{+}{ }^{+} \mathrm{T}$ cells purified from vaccinated mice (Fig. 3e).

\section{Analysis of V3-specific CD8 T-cell response}

Since $\mathrm{CD}^{+} \mathrm{T}$ cells control the replication of highly pathogenic immunodeficiency viruses $[29,30]$, we also investigated the antigen-specific $\mathrm{CD} 8^{+} \mathrm{T}$-cell response following the intranasal route. One week after the final boost, isolated splenocytes were analysed for IFN- $\gamma$ production after 6 days of in vitro stimulation with V3pulsed LPS-blasts. In Fig. 4 we reported the percentage values of V3-specific IFN- $\gamma$ producing $\mathrm{CD}^{+} \mathrm{T}$ cells (Fig. 4a) and representative dot plots of ICS (Fig. 4b). Intranasal administration of Env(V3)-E2 particles was able to induce V3-specific $\mathrm{CD}^{+} \mathrm{T}$ cells that produced IFN- $\gamma$.

\section{Analysis of transcriptome profile of E2-pulsed BMDCs}

We used genome-wide transcriptional approach to identify gene expression signatures induced in antigen presenting cells by $\mathrm{E} 2$ vaccine, to understand and elucidate the molecular mechanisms that account for the E2-primed
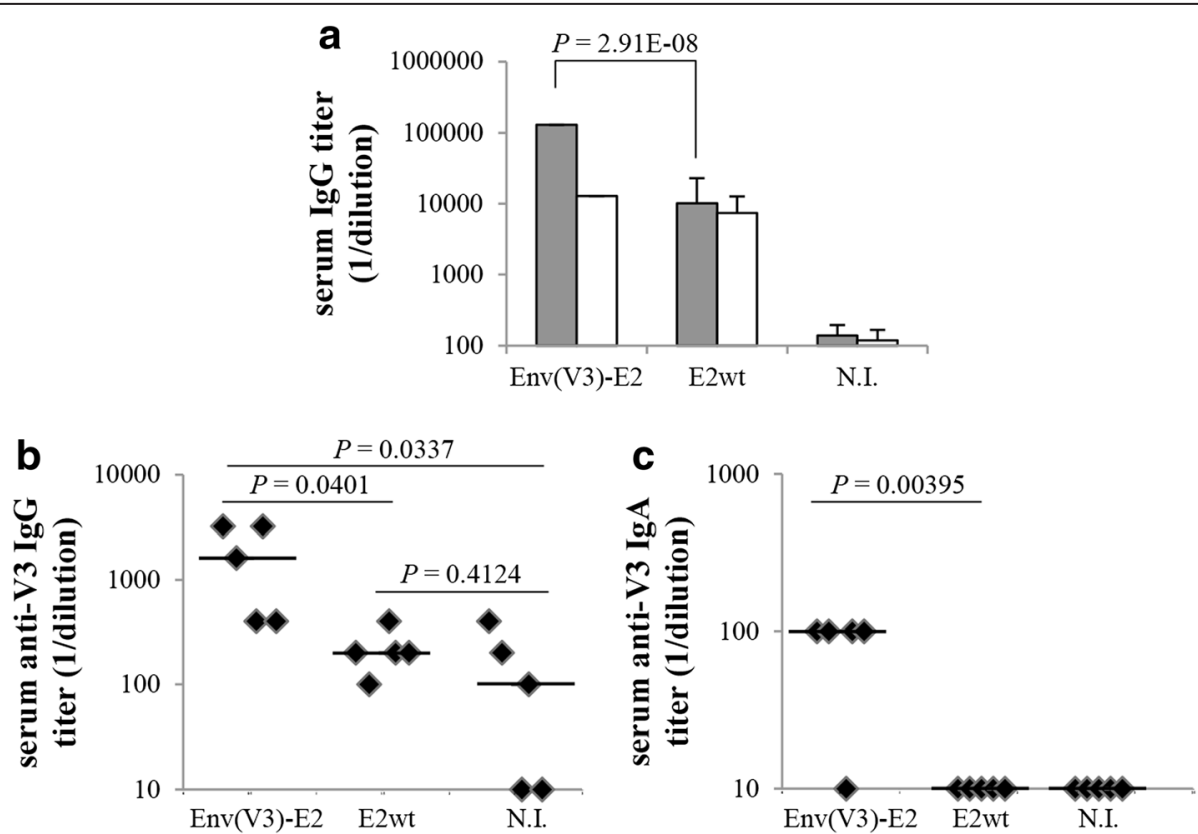

Fig. 2 Systemic antibody responses. BALB/c mice $(n=5)$ were intranasally immunized with Env(V3)-E2 plus CT adjuvant or E2wt particles. At the end of vaccination, sera were collected to determine binding antibody responses against (a) E2wt (white bars), Env(V3)-E2 protein (gray bars) and (b-c) HIV-1 SF162 V3 synthetic peptide, by ELISA. Results were expressed as reciprocal endpoint titers. Naïve mouse group (N.I., $n=5)$ was used as control of background response. a Anti-carrier E2 and anti- Env-E2 IgG antibodies. Mean values + S.D. are shown. b Anti-V3 IgG and c anti-V3 serum IgA binding antibodies obtained from sera of each animal. Lines represent median values. $P$ values determined using the unpaired two-tailed Student's t-test are reported. A representative experiment out of two is shown 


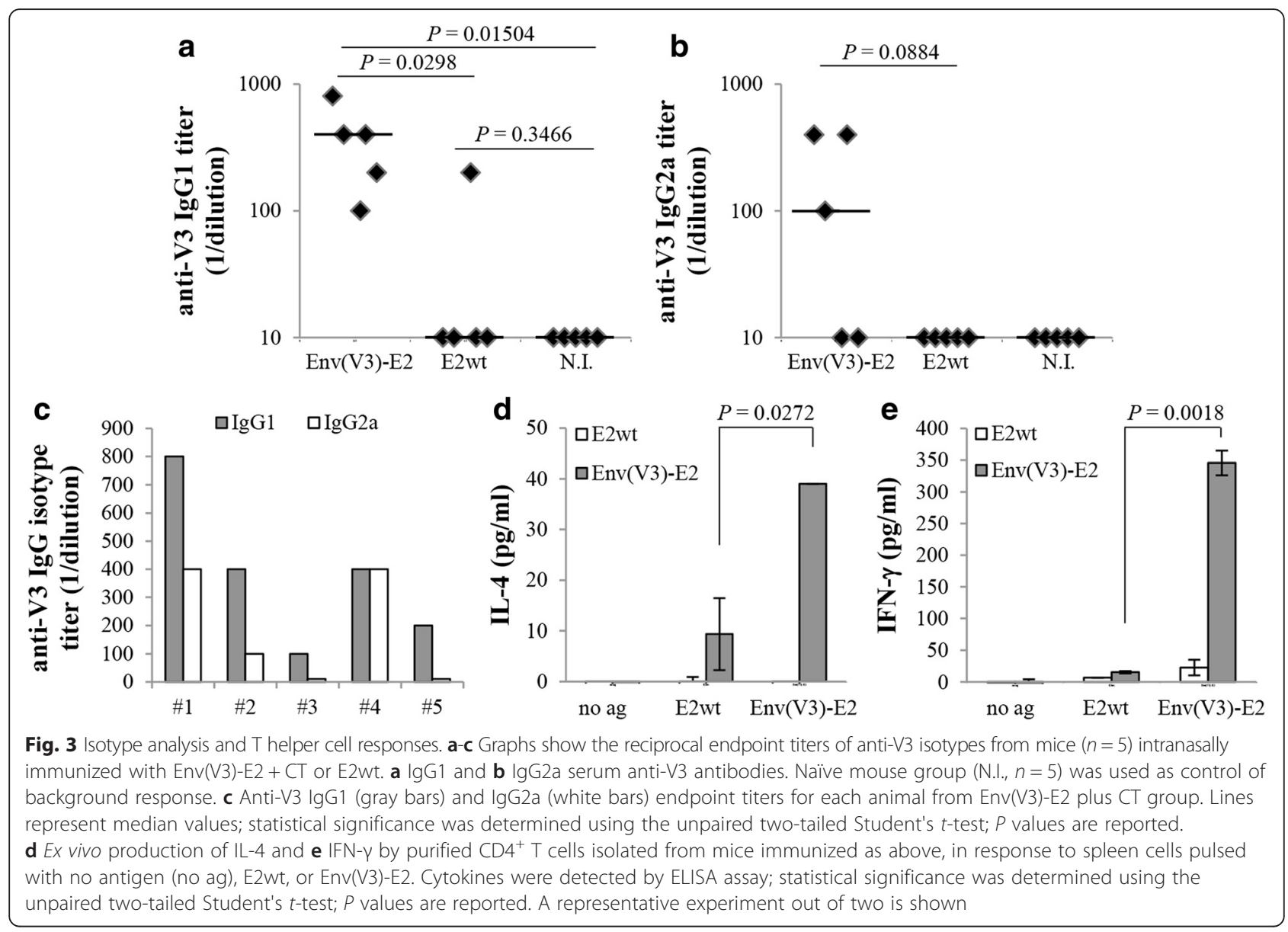

immune responses. In detail, we performed RNASequencing analysis on mouse immature BMDCs cultured with LPS-free E2wt particles to explore the impact of E2 scaffold on the transcriptional profile of BMDCs. Comparing the transcriptome of un-pulsed BMDCs with the transcriptome of E2-treated cells, we observed a substantial deregulation of gene expression after E2 treatment (more than 5300 genes with FDR $<0.05$ ). In particular, a significant up-regulation was measured for 2984 genes upon E2 stimulation (Fig. 5a). Statistically significant molecular pathways perturbed in E2-pulsed BMDCs were defined by mapping up-regulated genes to KEGG (Kyoto Encyclopedia of Genes and Genomes) pathways using the Database for Annotation, Visualization and Integrated Discovery [27]. Such analysis revealed that E2 exposure triggers the up-regulation of genes associated with immune response, such as the "Chemokine signaling" and the "Jak-STAT signaling" pathways, and the expression levels of selected genes involved in these pathways are illustrated in Fig. 5b. Interestingly, RNASeq data revealed a significant up-regulation of genes correlated with type- 2 polarized DCs (green asterisks in Fig. 5a and b). Among them, a significant transcriptional activation was measured for genes encoding Janus Kinase
2 (Jak2 gene), the Signal Transducer and Activator of Transcription 5, STAT5 (Stat5a and Stat5b genes), the transcription factor Nf-kB (Nfkb1), the Th2 chemokine CCL17 (Ccl17 gene), the Notch ligand Jagged-1 protein (Jag1 gene) and Interferon regulatory factor 4 (Irf4 gene). Notably, an opposite expression trend was observed for genes encoding proteins related to Th1 cell polarization. In particular, interferon signaling genes such as Stat1 and Irf7, and chemokine and interleukin encoding genes - including Cxcl10 and Il15 - were significantly down-modulated after BMDC exposure to E2 compared to untreated cells (red asterisks in Fig. $5 \mathrm{a}$ and b). Since the expression of Irf4 has been positively correlated to a transcriptional activation of Th2 polarization-related genes [31], we investigated the expression level of these genes. In particular, RNA-Seq analysis revealed that Itgam (integrin alpha M), Pdcd1lg2 (programmed cell death 1 ligand 2), and Ciita (class II, major histocompatibility complex, transactivator) genes were up-regulated in DCs exposed to E2. Furthermore, in E2-pulsed BMDCs, Il12b, Il6 and other genes encoding receptors of innate immune system such as Nlrp3 (NOD-like receptor family, pyrin domain containing 3), Tlr2 (toll-like receptor 2) and Il7r (interleukin 7 receptor) genes - were up-regulated. In addition, the 


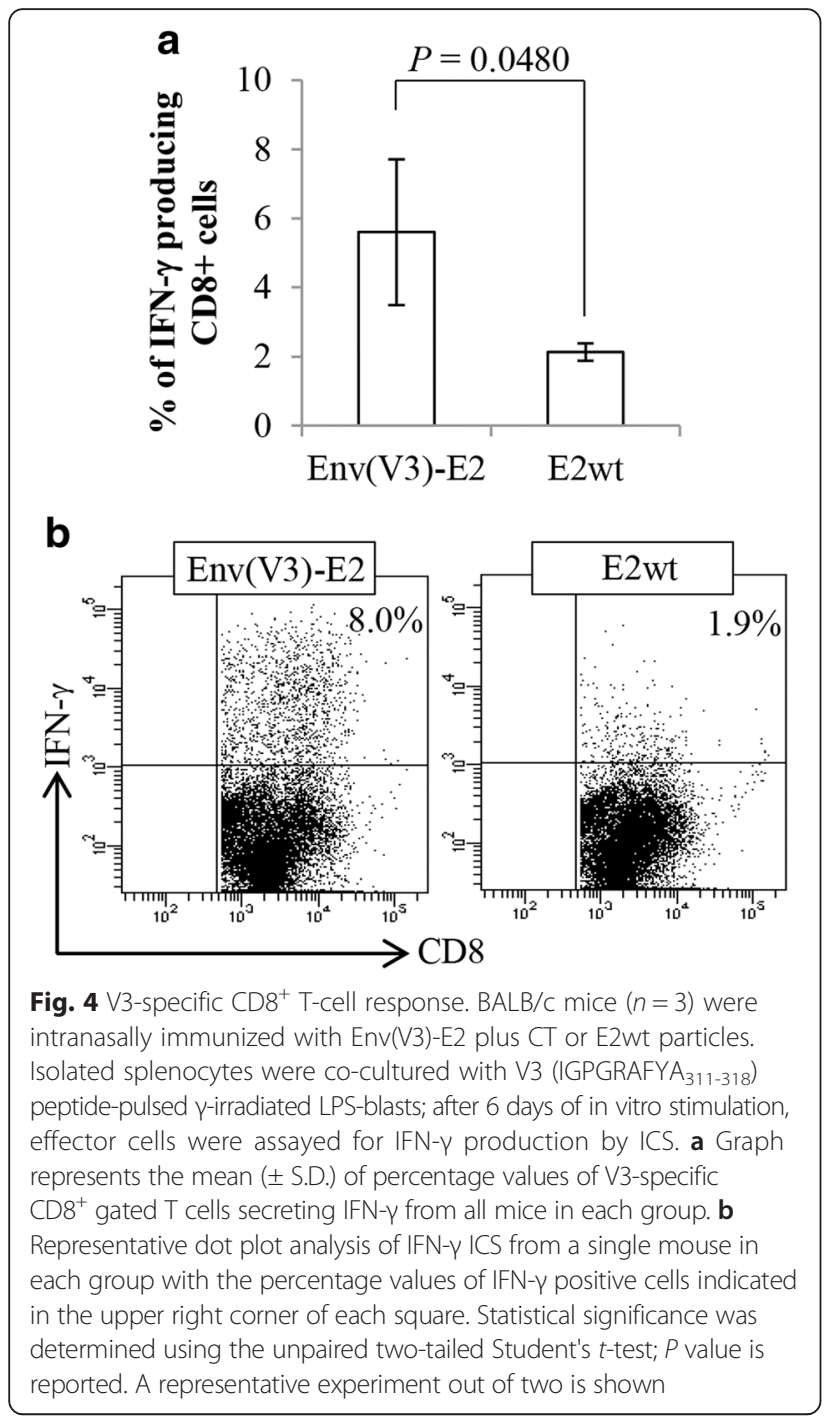

expression levels of genes encoding the co-stimulatory molecule CD40 and the Notch2 signaling components (Notch2, Rbpj, Mib1) increased when BMDCs were stimulated with E2 (Fig. 5b). It should be emphasized that the Notch2-RBPJ signaling receptor has been described to control functional differentiation of DCs and specify a

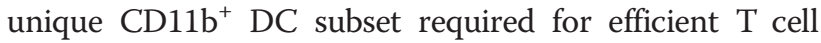
priming [32]. These results suggest that E2 scaffold may activate DCs through innate immune receptor (PRRs, pattern recognition receptors) and provide signals that program DCs to prime Th2 cells, through the expression of a Th2-type DC signature.

\section{Discussion}

Specific immune responses are characterized by different patterns of cytokines produced by $\mathrm{CD} 4^{+} \mathrm{T}$ cells, an event known as polarization of helper $\mathrm{T}$ cells and there can be striking differences in the type of response preferentially stimulated by different carriers and/or adjuvants. In the context of a vaccine formulation, it is important to dissect the polarization induced by the E2 carrier in order to understand how to best deliver and eventually combine immunogens.

We previously described that subcutaneous administration of E2 particles expressing the Env(V3) hypervariable region elicited a sustained immune response by inducing both antibodies and antigen specific T cells [7]. Here we report that mucosally administered $\operatorname{Env}(\mathrm{V} 3)$-E2 were also able to elicit mucosal and systemic V3-specific humoral immune responses. Due to the limited sample volume obtained from mice we were not able to assess the neutralization activity of the antibodies induced by E2 immunization. However, it should be emphasized that preclinical studies of HIV-1 vaccine candidates have typically shown that neutralizing antibodies (NAbs) with a long heavy chain complementarity-determining region 3 (HCDR3) are found in non-human primate and rabbit animal models, with the latter being currently the favorite model for testing candidates at eliciting NAbs. We previously reported that our Env(V3)-E2 construct was able to induce autologous NAbs when administered subcutaneously in rabbits, with a modest level of neutralization of some Tier 1 viruses [7]. For this reason we plan to assess in future work using larger animal models the induction of neutralizing antibodies by E2 mucosal immunization.

Here we also report that intranasal administration of Env(V3)-E2 particles elicits antigen-specific splenic CD8 ${ }^{+}$ and $\mathrm{CD}^{+} \mathrm{T}$ cells. The IgG1/IgG2a ratio in the sera and the ability of Env-E2 specific CD $4^{+} \mathrm{T}$ cells to produce IL-4 suggest that a Th2-type of immune response is induced in mice also after mucosal immunization. Th2-type CD4 Tcell polarization has been reported to favor mucosal IgA responses [33]. Indeed, we observed the presence of V3specific IgA in feces and anti-V3 IgG in sera of vaccinated mice following E2 mucosal administration. Since the contribution of monomeric IgA, essentially transudated serum IgA, to total IgA in fecal samples has been previously found negligible in comparison to the mucosally secreted dimeric IgA (generally less than $0.1 \%$ ) [34], we can assume that the IgA in feces from vaccinated mice were mainly of the secretory type. However, we cannot exclude the presence of monomeric IgA. In contrast to previous results obtained by subcutaneous administration [5, 28], here, we observed the ability of antigen-specific $\mathrm{CD} 4^{+} \mathrm{T}$ cells to produce IFN- $\gamma$. These data indicate the presence of Th2 and Th1-polarized $\mathrm{T}$ cells following mucosal immunization in agreement with reports demonstrating a Th1 switch in mucosally primed mice [35]. However, from our data, we cannot exclude that the production of these two cytokines may depend on the same cells.

Using an in vitro system, we measured the ability of E2 scaffold to induce gene expression changes in antigen 


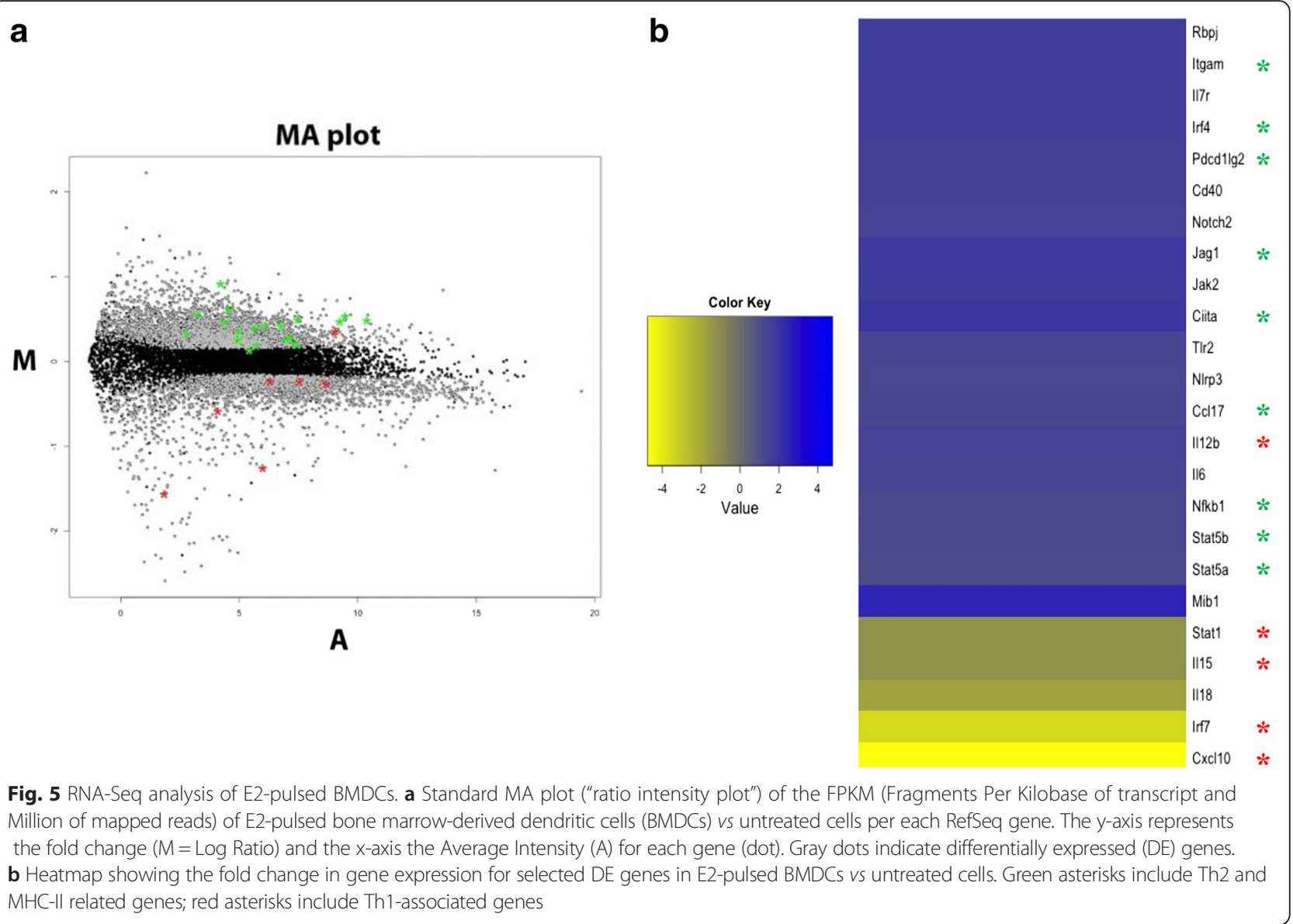

presenting cells. We profiled the entire transcriptome of BMDCs stimulated with the E2 scaffold, showing a significant up-regulation of genes associated with Th2polarizing DC capability [36]. Notably, we observed a significant up-regulation of the gene encoding the Notch ligand Jagged 1 (encoded by Jag1). Its expression in DCs has been previously described to support Notch-mediated Th2 differentiation [37]. In addition, we reported the upregulation of Stat5 and $N f k b 1$, whose expression is required within DC in promoting Th2 immunity [38, 39], and of Irf4, known to regulate the transcription of key cytokines involved in the immune response [40]. Irf4 expression in DC has been very recently described to play a role in the initiation of the Th2 cell response [41, 42]. Previous findings also revealed that Irf4 expression is significantly correlated with the expression of CD11b (encoded by Itgam), programmed death ligand-2 (encoded by $P d c d 1 \lg 2)$ and MHC class II major histocompatibility complex transactivator (encoded by Ciita) [31]. In agreement with this study, we report here the up-regulation of these genes in E2-stimulated DCs.

The results obtained from the transcriptome analysis by RNA-Seq for E2-pulsed BMDCs confirm, and further strengthen, our previous observations and findings. Indeed, we have reported that subcutaneous vaccination of C57BL/ 6 mice with E2 polarizes the immune response towards a high IgG1/IgG2a isotype ratio and induces IL-4 producing $\mathrm{CD}^{+}{ }^{+} \mathrm{T}$ cells, even in Th1-prone strains [28]. We also observed this type of polarization when subcutaneous administration of $\mathrm{E} 2$ particles was performed in the absence or in presence of various types of adjuvants, such as the strong reactogenic CFA (Freund's Complete Adjuvant) or in formulation suitable for human use, as alum (Allhidrogel) or squalen-based oil in water emulsion (Addavax) [43]. However, when we administered E2 with another carrier, namely the filamentous bacteriophage fd which we know to prompt Th1 polarization, in a priming-boosting strategy, we demonstrated a shift towards a mixed Th1/Th2 type of polarized response [28], indicating that it is also possible to modulate the Th2-type of the immune response induced by E2 administration.

E2 particles free of endotoxin, administered subcutaneously in the absence of added adjuvants, are also immunogenic, although the addition of adjuvants increases the magnitude of the response [7]. However, in this case of mucosal administration we could not detect antigenspecific immune response in the absence of adjuvant administration. Indeed, RNA-Seq analysis indicates that 
endotoxin-free E2 particles are able to activate in DCs pathways of immune response as the chemokine and the Jak-STAT signaling pathways. Moreover, the upregulated expression of $I l 12$ and $I l 6$ was found, while the expression levels of genes encoding other proinflammatory cytokines did not increase upon E2 stimulation. These levels of inflammatory response may explain why E2 particles free of endotoxin are immunogenic when administered subcutaneously in the absence of added adjuvants. However, it is not sufficient to prime the immune response in the absence of adjuvants in the case of mucosal delivery.

We previously have reported that Env(V3)-E2 particles were much more immunogenic when co-administered with other systems such DNA expression vectors, encoding Env proteins, delivered intradermally (via Gene gun) in rabbits [7]. On the basis of these findings and of the known role played by Th2 cells in activating and enhancing B cell proliferation and humoral immune responses [44], in order to increase the mucosal immune response we plan, in future work, to test the mucosal delivery of E2 particles in combination with other strongly immunogenic delivery systems.

\section{Conclusions}

In the current preclinical study we showed that E2 scaffold is immunogenic when administered via mucosal route in the presence of adjuvant and thus may represent a relevant option for immunization against pathogens whose infections occur or initiate at a mucosal surface. Moreover, by using a genome-wide transcriptional approach, we attempted to dissect the mechanisms by which DCs may orchestrate the immune response following vaccination with the E2 scaffold.

\begin{abstract}
Abbreviations
APCs, antigen presenting cells; BMDC, bone marrow-derived dendritic cell; CFA, freund's complete adjuvant; $C T$, cholera toxin; CTL, cytotoxic T lymphocytes; DCs, dendritic cells; E2wt, E2 wild-type; Env, envelope; EU, endotoxin unit; FACS, fluorescent activated cell sorter; FCS, fetal calf serum; FDR, false discovery rate; FITC, fluorescein isothiocyanate; FPKM, fragments per kilobase of transcript and million mapped reads; GM-CSF, granulocyte-macrophage colony-stimulating factor; ICS, intracellular cytokine staining; IFN, interferon; Ig, immunoglobulin; IL, interleukin; IN, intranasal administration; LAL, Limulus Amebocyte Lisate; LPS, lipopolysaccharide; MHC, major histocompatibility complex; NAbs, neutralizing antibodies; OD, optical density; PBS, phosphate buffer saline; PDH, pyruvate dehydrogenase; PE, phycoerythrin; PRRs, pattern recognition receptors; RNA-Seq, RNA-Sequencing; Th, Thelper
\end{abstract}

\section{Acknowledgements}

We would like to thank the IGB-IBP FACS Facility, at CNR, Naples; the Animal House Facility at CNR, Avellino; Dr. Marianna Aprile and Dr. Margherita Scarpato (from IGB "A. Buzzati-Traverso", CNR, Naples) for the construction of the libraries for the RNA-Seq experiments; the NGS Facility of TIGEM for the Illumina platform.

\section{Funding}

This work was supported by NIH (US) PHS grants R01-AI074379, MIUR-PON 01_00117, "Progetto Invecchiamento" C.N.R., and Regione Campania PO FESR 2007/2013. The funding sources had no role in study design, in the collection, analysis and interpretation of data, in the writing of the manuscript, and decision of publication.

\section{Availability of data and materials}

The datasets supporting the conclusions of this article are available in the G.E.O. (Gene Expression Omnibus) repository (identifier: GSE60231; http://www.ncbi.nlm.nih.gov/geo/).

\section{Competing interests}

The authors declare that they have no competing interests.

\section{Authors' contributions}

MT designed and performed experiments, analyzed data, and wrote the manuscript. FM performed mucosal vaccinations and antibody assays. LDA, RS and FC performed cellular assays and critically reviewed the manuscript. VC performed the RNA-Seq and the bioinformatic analysis. AP, SPM, SJK, and NLH contributed to study design and interpretation of data, and critically reviewed the manuscript. AC supervised bioinformatics analysis. MR supervised mucosal experiments and helped to draft the manuscript. PDB supervised the project and wrote the manuscript. All authors read and approved the final manuscript.

\section{Consent for publication}

Not applicable.

\section{Ethics approval and consent to participate}

All experiments with mice were performed in accordance with European Union Laws and guidelines. All animal studies were approved by the national institutional review committee of Health Ministry, General Division of Animal Health and of Veterinary Medicine, and performed according with European regulations (EU Directive 2010/63/EU). Animals were housed under specific pathogen free conditions at the Animal Facility of the Institute of Food Science of C.N.R., Avellino, Italy (accreditation no. DM.161/99).

\section{Author details}

'Institute of Protein Biochemistry, C.N.R, Via Pietro Castellino 111, Naples 80131, Italy. ${ }^{2}$ Institute of Food Sciences, C.N.R, Via Roma 64, Avellino 83100, Italy. ${ }^{3}$ Institute of Genetics and Biophysics A. Buzzati-Traverso, C.N.R, Via Pietro Castellino 111, Naples 80131, Italy. ${ }^{4}$ Division of Pathobiology and Immunology, Oregon National Primate Research Center, Oregon Health \& Science University, 505 NW 185th Avenue, Beaverton, OR 97006, USA. 5Department of Science and Technology, University of Naples "Parthenope", Centro Direzionale Site island C4, Naples 80143, Italy.

Received: 19 January 2016 Accepted: 12 July 2016

Published online: 16 July 2016

\section{References}

1. Domingo GJ, Chauhan HJ, Lessard IA, Fuller C, Perham RN. Self-assembly and catalytic activity of the pyruvate dehydrogenase multienzyme complex from Bacillus stearothermophilus. Eur J Biochem. 1999;266(3):1136-46.

2. Domingo GJ, Orru' S, Perham RN. Multiple display of peptides and proteins on a macromolecular scaffold derived from a multienzyme complex. J Mol Biol. 2001;305(2):259-67.

3. Domingo GJ, Caivano A, Sartorius R, Barba P, Bäckström M, Piatier-Tonneau $D$, Guardiola J, De Berardinis P, Perham RN. Induction of specific T-helper and cytolytic responses to epitopes displayed on a virus-like protein scaffold derived from the pyruvate dehydrogenase multienzyme complex. Vaccine. 2003;21(13-14):1502-9.

4. De Berardinis P, Sartorius R, Caivano A, Mascolo D, Domingo GJ, Del Pozzo G, Gaubin M, Perham RN, Piatier-Tonneau D, Guardiola J. Use of fusion proteins and procaryotic display systems for delivery of HIV-1 antigens: development of novel vaccines for HIV-1 infection. Curr HIV Res. 2003;1(4):441-6.

5. Caivano A, Doria-Rose NA, Buelow B, Sartorius R, Trovato M, D'Apice L, Domingo GJ, Sutton WF, Haigwood NL, De Berardinis P. HIV-1 Gag p17 presented as virus-like particles on the E2 scaffold from Geobacillus stearothermophilus induces sustained humoral and cellular immune responses in the absence of IFNy production by CD4+ T cells. Virology. 2010;407(2):296-305. doi:10.1016/j.virol.2010.08.026

6. De Berardinis P. Haigwood NL. New recombinant vaccines based on the use of prokaryotic antigen-display systems. Expert Rev Vaccines. 2004;3(6):673-9. 
7. Jaworski JP, Krebs SJ, Trovato M, Kovarik DN, Brower Z, Sutton WF, Waagmeester G, Sartorius R, D'Apice L, Caivano A, Doria-Rose NA, Malherbe D, Montefiori DC, Barnett S, De Berardinis P, Haigwood NL. Coimmunization with multimeric scaffolds and DNA rapidly induces potent autologous HIV-1 neutralizing antibodies and CD8+ T cells. PLoS One. 2012; 7(2), e31464. doi:10.1371/journal.pone.0031464.

8. Poles J, Alvarez Y, Hioe CE. Induction of Intestinal Immunity by Mucosal Vaccines As a Means of Controlling HIV Infection. AIDS Res Hum Retroviruses. 2014;30(11):1027-40. doi:10.1089/aid.2014.0233.

9. Belyakov IM, Hel Z, Kelsall B, Kuznetsov VA, Ahlers JD, Nacsa J, Watkins DI, Allen TM, Sette A, Altman J, Woodward R, Markham PD, Clements JD, Franchini G, Strober W, Berzofsky JA. Mucosal AIDS vaccine reduces disease and viral load in gut reservoir and blood after mucosal infection of macaques. Nat Med. 2001;7(12):1320-6.

10. Revaz V, Nardelli-Haefliger D. The importance of mucosal immunity in defense against epithelial cancers. Curr Opin Immunol. 2005;17(2):175-9.

11. Gallichan WS, Rosenthal KL. Long-lived cytotoxic T lymphocyte memory in mucosal tissues after mucosal but not systemic immunization. J Exp Med. 1996:184(5):1879-90.

12. Pavot V, Rochereau N, Genin C, Verrier B, Paul S. New insights in mucosal vaccine development. Vaccine. 2012:30(2):142-54. doi:10.1016/:vaccine.2011.11.003.

13. Wang J, Thorson L, Stokes RW, Santosuosso M, Huygen K, Zganiacz A, Hitt M, Xing Z. Single mucosal, but not parenteral, immunization with recombinant adenoviral-based vaccine provides potent protection from pulmonary tuberculosis. J Immunol. 2004;173(10):6357-65.

14. Bomsel M, Tudor D, Drillet AS, Alfsen A, Ganor Y, Roger MG, Mouz N, Amacker M, Chalifour A, Diomede L, Devillier G, Cong Z, Wei Q, Gao H, Qin C, Yang GB, Zurbriggen R, Lopalco L, Fleury S. Immunization with HIV-1 gp41 subunit virosomes induces mucosal antibodies protecting nonhuman primates against vaginal SHIV challenges. Immunity. 2011;34(2):269-80. doi:10.1016/j.immuni.2011.01.015.

15. Pulendran B, Li S, Nakaya HI. Systems vaccinology. Immunity. 2010;33(4): 516-29. doi:10.1016/j.jmmuni.2010.10.006.

16. Li S, Rouphael N, Duraisingham S, Romero-Steiner S, Presnell S, Davis C, Schmidt DS, Johnson SE, Milton A, Rajam G, Kasturi S, Carlone GM, Quinn C, Chaussabel D, Palucka AK, Mulligan MJ, Ahmed R, Stephens DS, Nakaya HI, Pulendran B. Molecular signatures of antibody responses derived from a systems biology study of five human vaccines. Nat Immunol. 2014;15(2): 195-204. doi:10.1038/ni.2789.

17. Haddad EK, Pantaleo G. Systems biology in the development of HIV vaccines. Curr Opin HIV AIDS. 2012;7(1):44-9. doi:10.1097/COH.0b013e32834ddcc3.

18. Lessard IA, Domingo GJ, Borges A, Perham RN. Expression of genes encoding the E2 and E3 components of the Bacillus stearothermophilus pyruvate dehydrogenase complex and the stoichiometry of subunit interaction in assembly in vitro. Eur J Biochem. 1998:258(2):491-501.

19. Aida Y, Pabst MJ. Removal of endotoxin from protein solutions by phase separation using Triton X-114. J Immunol Methods. 1990;132(2):191-5.

20. Isticato R, Sirec T, Treppiccione L, Maurano F, De Felice M, Rossi M, Ricca E. Non-recombinant display of the $B$ subunit of the heat labile toxin of Escherichia coli on wild type and mutant spores of Bacillus subtilis. Microb Cell Fact 2013:12:98 doi:10.1186/1475-2859-12-98.

21. Yamazaki M, Kitamura R, Kusano S, Eda H, Sato S, Okawa-Takatsuji M, Aotsuka S, Yanagi K. Elevated immunoglobulin G antibodies to the prolinerich amino-terminal region of Epstein-Barr virus nuclear antigen-2 in sera from patients with systemic connective tissue diseases and from a subgroup of Sjögren's syndrome patients with pulmonary involvements. Clin Exp Immunol. 2005:139(3):558-68.

22. Lutz MB, Kukutsch N, Ogilvie AL, Rössner S, Koch F, Romani N, Schuler G. An advanced culture method for generating large quantities of highly pure dendritic cells from mouse bone marrow. J Immunol Methods. 1999;223(1):77-92

23. Costa V, Angelini C, D'Apice L, Mutarelli M, Casamassimi A, Sommese L, Gallo MA, Aprile M, Esposito R, Leone L, Donizetti A, Crispi S, Rienzo M, Sarubbi B, Calabrò R, Picardi M, Salvatore P, Infante T, De Berardinis P, Napoli C, Ciccodicola A. Massive-scale RNA-Seq analysis of non ribosomal transcriptome in human trisomy 21. PLoS One. 2011;6(4):e18493. doi:10.1371/journal.pone.0018493

24. Kim D, Pertea G, Trapnell C, Pimentel H, Kelley R, Salzberg SL. TopHat2: accurate alignment of transcriptomes in the presence of insertions, deletions and gene fusions. Genome Biol. 2013;14(4):R36. doi:10.1186/gb-2013-14-4-r36.

25. Trapnell C, Williams BA, Pertea G, Mortazavi A, Kwan G, van Baren MJ, Salzberg SL, Wold BJ, Pachter L. Transcript assembly and quantification by
RNA-Seq reveals unannotated transcripts and isoform switching during cell differentiation. Nat Biotechnol. 2010;28(5):511-5. doi:10.1038/nbt.1621.

26. Trapnell C, Roberts A, Goff L, Pertea G, Kim D, Kelley DR, Pimentel H, Salzberg SL, Rinn JL, Pachter L. Differential gene and transcript expression analysis of RNA-seq experiments with TopHat and Cufflinks. Nat Protoc. 2012;7(3):562-78. doi:10.1038/nprot.2012.016.

27. da Huang W, Sherman BT, Lempicki RA. Systematic and integrative analysis of large gene lists using DAVID bioinformatics resources. Nat Protoc. 2009: 4(1):44-57. doi:10.1038/nprot.2008.211.

28. Mantile F, Basile C, Cicatiello V, De Falco D, Caivano A, De Berardinis P, Prisco A. A multimeric immunogen for the induction of immune memory to beta-amyloid. Immunol Cell Biol. 2011;89(5):604-9. doi:10.1038/icb.2010.134.

29. Mudd PA, Martins MA, Ericsen AJ, Tully DC, Power KA, Bean AT, Piaskowski SM, Duan L, Seese A, Gladden AD, Weisgrau KL, Furlott JR, Kim YI, de Santana MG V, Rakasz E, Capuano 3rd S, Wilson NA, Bonaldo MC, Galler R, Allison DB, Piatak Jr M, Haase AT, Lifson JD, Allen TM, Watkins DI. Vaccineinduced CD8+ T cells control AIDS virus replication. Nature. 2012;491 (7422): 129-33. doi:10.1038/nature11443.

30. Hansen SG, Piatak Jr M, Ventura AB, Hughes CM, Gilbride RM, Ford JC, Oswald K, Shoemaker R, Li Y, Lewis MS, Gilliam AN, Xu G, Whizin N, Burwitz BJ, Planer SL, Turner JM, Legasse AW, Axthelm MK, Nelson JA, Früh K, Sacha JB, Estes JD, Keele BF, Edlefsen PT, Lifson JD, Picker LJ. Immune clearance of highly pathogenic SIV infection. Nature. 2013; 502(7469):100-4. doi:10.1038/nature12519.

31. Vander Lugt B, Khan AA, Hackney JA, Agrawal S, Lesch J, Zhou M, Lee WP, Park S, Xu M, DeVoss J, Spooner CJ, Chalouni C, Delamarre L, Mellman I, Singh $\mathrm{H}$. Transcriptional programming of dendritic cells for enhanced MHC class II antigen presentation. Nat Immunol. 2014;15(2):161-7. doi:10.1038/ni.2795.

32. Lewis $\mathrm{KL}$, Caton ML, Bogunovic M, Greter M, Grajkowska LT, Ng D, Klinakis A Charo IF, Jung S, Gommerman JL, Ivanov II, Liu K, Merad M, Reizis B. Notch2 receptor signaling controls functional differentiation of dendritic cells in the spleen and intestine. Immunity. 2011;35(5):780-91. doi:10.1016/j.immuni.2011.08.013.

33. Yamamoto M, Vancott JL, Okahashi N, Marinaro M, Kiyono H, Fujihashi K, Jackson RJ, Chatfield SN, Bluethmann H, McGhee JR. The role of Th1 and Th2 cells for mucosal IgA responses. Ann N Y Acad Sci. 1996;778:64-71.

34. Meckelein B, Externest D, Schmidt MA, Frey A. Contribution of serum immunoglobulin transudate to the antibody immune status of murine intestinal secretions: influence of different sampling procedures. Clin Diagn Lab Immunol. 2003;10(5):831-4.

35. Fiorino F, Pettini E, Pozzi G, Medaglini D, Ciabattini A. Prime-boost strategies in mucosal immunization affect local IgA production and the type of th response. Front Immunol. 2013;4:128. doi:10.3389/fimmu. 2013.00128.

36. Hussaarts L, Yazdanbakhsh M, Guigas B. Priming dendritic cells for th2 polarization: lessons learned from helminths and implications for metabolic disorders. Front Immunol. 2014;5:499. doi:10.3389/fimmu.2014.00499.

37. Amsen D, Blander JM, Lee GR, Tanigaki K, Honjo T, Flavell RA. Instruction of distinct CD4 Thelper cell fates by different notch ligands on antigenpresenting cells. Cell. 2004:117(4):515-26.

38. Bell BD, Kitajima M, Larson RP, Stoklasek TA, Dang K, Sakamoto K, Wagner KU, Kaplan DH, Reizis B, Hennighausen L, Ziegler SF. The transcription factor STAT5 is critical in dendritic cells for the development of TH2 but not TH1 responses. Nat Immunol. 2013;14(4):364-71. doi:10.1038/ni.2541.

39. Artis D, Kane CM, Fiore J, Zaph C, Shapira S, Joyce K, Macdonald A, Hunter C, Scott P, Pearce EJ. Dendritic cell-intrinsic expression of NF-kappa B1 is required to promote optimal Th2 cell differentiation. J Immunol. 2005;174(11):7154-9.

40. Murphy KM. Transcriptional control of dendritic cell development. Adv Immunol. 2013:120:239-67. doi:10.1016/B978-0-12-417028-5.00009-0.

41. Williams JW, Tjota MY, Clay BS, Vander Lugt B, Bandukwala HS, Hrusch CL, Decker DC, Blaine KM, Fixsen BR, Singh H, Sciammas R, Sperling Al. Transcription factor IRF4 drives dendritic cells to promote Th2 differentiation. Nat Commun. 2013:4:2990. doi:10.1038/ncomms3990.

42. Gao Y, Nish SA, Jiang R, Hou L, Licona-Limón P, Weinstein JS, Zhao H, Medzhitov R. Control of T helper 2 responses by transcription factor IRF4-dependent dendritic cells. Immunity. 2013;39(4):722-32. doi:10.1016/j.immuni.2013.08.028.

43. Mantile F, Trovato M, Santoni A, Barba P, Ottonello S, De Berardinis P, Prisco A. Alum and squalene-oil-in-water emulsion enhance the titer and avidity of anti-A $\beta$ antibodies induced by multimeric protein antigen (1-11)E2, 
preserving the lgg1-skewed isotype distribution. PLoS One. 2014;9(7), e101474. doi:10.1371/journal.pone.0101474.

44. Didierlaurent AM, Morel S, Lockman L, Giannini SL, Bisteau M, Carlsen H, Kielland A, Vosters O, Vanderheyde N, Schiavetti F, Larocque D, Van

Mechelen M, Garçon N. AS04, an aluminum salt- and TLR4 agonist-based adjuvant system, induces a transient localized innate immune response leading to enhanced adaptive immunity. J Immunol. 2009;183(10):6186-97. doi:10.4049/jimmunol.0901474.

Submit your next manuscript to BioMed Central and we will help you at every step:

- We accept pre-submission inquiries

- Our selector tool helps you to find the most relevant journal

- We provide round the clock customer support

- Convenient online submission

- Thorough peer review

- Inclusion in PubMed and all major indexing services

- Maximum visibility for your research

Submit your manuscript at www.biomedcentral.com/submit 